\title{
Late Career Job Loss and the Decision to Retire*
}

\author{
Irina Merkurieva ${ }^{1}$ \\ School of Economics and Finance, University of St Andrews, United \\ Kingdom \\ E-mail: i.merkurieva@st-andrews.ac.uk.
}

Shortened title: Late Career Job Loss

\begin{abstract}
This paper provides an empirical analysis of the effect of involuntary job loss on the lifetime income and labor supply of older workers. I develop and estimate a dynamic programming model of retirement with savings, costly job search and exogenous layoffs. The average cost of job loss is equivalent to one year of pre-displacement earnings, $70 \%$ due to the wage reduction and $30 \%$ to the search frictions. Displaced workers on average retire fourteen months earlier. Workers who approached retirement during the Great Recession will work approximately five months longer in response to the contemporaneous financial and labor market shocks.
\end{abstract}

Keywords: retirement, life-cycle labor supply, layoff cost, saving, cyclical unemployment

JEL classification: J14, J26, J64

*Manuscript submitted on May 2, 2016. Revised on December 21, 2017.

${ }^{1}$ I am very grateful to John Kennan, J. Karl Scholz and James Walker for their guidance and support. I also thank J. David Brown, Charles Becker, Chao Fu, Rasmus Lentz, Rebecca Lessem, Christopher Taber, Giorgio Topa, Wilbert van der Klaauw and seminar participants at the University of Wisconsin and the Federal Reserve Bank of New York for their helpful comments. James Walker helped me to 


\section{Introduction}

Every year over the last decade, well over a million U.S. workers age 55 and older lost their jobs to layoffs. More than one fifth of the 2010 population between ages 60 and 65 have been displaced at least once since turning fifty. In the meantime, the labor force participation of individuals older than 55 went up to 40 percent, a ten percentage point increase relative to 1990. As the fraction of people who remain employed well into their sixties keeps on growing, those workers increasingly rely on old age earnings. The exposure and vulnerability of an aging workforce to the consequences of job loss have manifested themselves most recently during the Great Recession, when unemployment rates among older persons have reached a historical maximum. ${ }^{2}$

In this paper I examine how job loss experienced by senior workers at different stages of the business cycle affects their labor force attachment, their take up of Social Security, and their lifetime income. I show that involuntary separation at older age results in substantial economic loss for the affected individuals. On average, the cost of job loss for a sixty year old male worker computed as an amount of compensation required to keep him indifferent between the states of employment and unemployment due to displacement amounts to thirty seven thousand dollars. This is approximately equivalent to an annual wage earned at this age, a large amount taking into account that the remaining work life for the majority of affected workers is relatively short. The main source of this cost is the reduction of post-displacement wages, which accounts for 70 percent of the total. The

get access to the restricted part of the HRS data. My work with the restricted data was supported by the Social Sciences Research Services at UW-Madison. The initial computations in this paper have been carried out with Flash High Performance Computing Cluster maintained by the Social Science Computing Cooperative at UW-Madison. All remaining errors are my own.

${ }^{2}$ Data sources: The number of workers displaced between 2001 and 2011 is computed from the Current Population Survey (CPS) Displaced Workers Supplement. The fraction of older workers affected by layoffs comes from the Health and Retirement Study (HRS) dataset. The labor force participation and unemployment rates are obtained from the CPS. 
remaining 30 percent are due to search frictions, including the cost of job search and the loss of earnings over the spells of unemployment that follow a job loss.

The effect of involuntary separations on the timing of retirement is not straightforward. Laid off individuals face the cost of searching for a new job that is likely to yield lower earnings. Displacement may encourage some of these workers to leave the labor force sooner than they had planned and to take up Social Security at an earlier age. Others may prefer to work longer to replenish their retirement savings that may have been depleted in the course of a post-displacement unemployment spell. These decisions will obviously depend on the labor market conditions and vary over the business cycle. The problem is further exacerbated by fluctuations in the value of retirement assets that, in recent years, have coincided with cyclical movements in the labor market.

This paper is the first to evaluate how retirement decisions are affected simultaneously by both labor market and asset shocks. The majority of displaced workers retires earlier than they would have had they not lost a job, by fourteen months on average. In the meantime, negative shocks to assets delay retirement from the labor force. I estimate that the cohort of workers who were approaching retirement at the onset of the Great Recession would tend to stay in the labor force approximately five months longer in response to the joint impact of changes in the value of household assets and the probabilities of losing and finding a job. Assuming the same cohort has been affected by the labor market conditions alone, their retirement would have happened approximately one and a half months sooner had they not experienced either labor market or asset shocks.

The paper also makes an important methodological contribution. Introducing labor market frictions into a life cycle model of labor supply, I show that involuntary job loss is a major retirement channel. Without search frictions, the model overestimates the rates of employment among seventy year old workers by eight percentage points. At this age, this is an understatement of retirement prevalence of 14 percent. In a frictionless environment, most of this difference is absorbed by the fixed cost of work. The fixed cost of work generates sharp retirement in many models, including French and Jones (2011). 
Rogerson and Wallenius (2013) argue that its typical estimated values are unrealistically high and lack solid economic interpretation. With search frictions, I increase the share of retirements that can be explained without relying on fixed cost by approximately ten percentage points.

My results stem from a dynamic programming model of optimal consumption and labor supply decisions with costly job search. The model includes uncertainty about survival, health status, medical expenses, asset returns, wages and availability of jobs. It accounts for Social Security rules, Medicare, employer provided health insurance, government transfers, unemployment insurance, taxes, and intentional bequests. The structural framework allows me to isolate the effect of layoffs, job finding and asset dynamics on the labor supply decisions of older workers. It also helps to define a relevant reference group for studying displaced workers. Varying the probabilities of job loss, job finding and asset returns, I account for the cyclical movements in the labor market along with the dynamics of the housing and stock prices. I estimate the model with the method of simulated moments using data from the Health and Retirement Study.

This paper is related to several strands in the literature. Most important, it builds upon earlier work on retirement from the labor force within the life cycle framework, including Blau and Gilleskie (2006, 2008); French and Jones (2011); Gustman and Steinmeier (1986); Haan and Prowse (2010, 2014); Rust and Phelan (1997); Scholz, et al. (2006); van der Klaauw and Wolpin (2008). I extend the results in this literature by incorporating exogenous layoffs, search frictions and time-varying asset returns. None of these previous papers accounts for the possibility of involuntary job loss followed by endogenous costly search. Adding these features, I address an entirely new set of questions about retirement behavior.

Next, I contribute to the literature focused on the economic cost of job loss (Farber 1993; Stevens 1997; Jacobson, et al. 1993; Couch and Placzek 2010; Davis and von Wachter 2011). This literature does not accommodate endogenous retirement, and produces mixed conclusions on the relationship between age and the cost of displacement. I 
fill in this gap by providing a detailed account of the cost of involuntary job loss for older workforce. A small number of papers evaluate the impact of layoffs on the employment of older workers (Chan and Stevens 2001, 2004; Elder 2004). My estimated probabilities of post-displacement employment rates are consistent with Chan and Stevens (2001), however I evaluate a broader range of displacement consequences, most important the economic cost of job loss over the business cycle and its sources. I also model a number of features that were not addressed in these other papers, yet are essential to the retirement behavior, such as health and unemployment insurance, medical expenses, Social Security take up, and the dynamics of the labor and financial markets. While Chan and Stevens (2004) found that pension-related incentives can only explain a small part of the observed changes in the timing of retirement associated with job loss, I show that post-displacement wage drop and search frictions can account for a large part of the response.

Finally, there is literature that analyzes the dynamics of retirement over the business cycle. Coile and Levine (2011a,b); Goda et al. (2011); McFall (2011) implemented a reduced form approach to study retirement during recessions. Gustman, et al. (2010) estimated the impact of the stock market decline on retirement using a life cycle model; however, they abstracted from the role of the labor market shocks. In contrast to the existing work, my model quantifies independent and combined long term effects of wealth changes, layoffs and job finding on the labor market behavior of older workers.

The rest of the paper is divided into seven sections. Section two provides the essential data facts on job loss and retirement. In section three I develop the life cycle model with labor market frictions. Section four describes the dataset used in the structural estimation, explains the choice of the estimation sample and initial conditions. Section five contains the details of the method of simulated moments and its implementation, as well as the estimation methods used to specify exogenous probability transitions and the policy environment. Section six discusses the estimates of the structural parameters. Section seven summarizes the results based on the counterfactuals and policy experiments. 
Section eight concludes.

\section{Facts about job loss and retirement}

I motivate the paper by highlighting the key facts on displacement and labor force attachment in the Health and Retirement Study (HRS, http://hrsonline.isr.umich.edu/), a nationally representative panel of individuals over the age of fifty. I document the prevalence of layoffs among older workers and estimate reduced form relationships between involuntary job loss, employment and earnings. ${ }^{3}$ The data analysis is based on employment histories of males between the ages of 50 and 80 that I construct using biennial data on their labor force status as well as employment changes reported between the survey waves.

The definition of involuntary job loss in this paper is based on self-reported reasons of employment termination. Involuntary job loss is represented by two of the separation reasons included in the HRS questionnaires, "laid off/let go" and "business closed". All other separation reasons, including quit, health, family, new job, retirement or financial incentives, are classified as quits. The dataset contains information on 3,093 layoffs that represent 30 percent of all reported separations. According to this definition, involuntary job loss is quite common among older workers, with one in six survey respondents having been laid off at least once.

This number should be treated as a lower bound because of possible misreporting of the separation reasons that has been documented in the literature. For example, Poterba and Summers (1984) find that 25 percent of the Current Population Study (CPS) quits have been reported as layoffs in the following survey month. Although the HRS only asks about the separation reason for each completed job spell once, adverse employment

\footnotetext{
${ }^{3}$ The terms layoff, job loss and displacement are used interchangeably throughout the paper. The intended meaning is best described as involuntary separation that is initiated by the firm rather than the worker, as opposed to a quit.
} 
changes that frequently precede quits suggest that some of them are not easy to distinguish from layoffs. Roughly 12 percent of the recorded quits have been encouraged by co-workers or happened in anticipation of layoff, reduction in wages or hours, or similar circumstances. Taking such instances into account, I conclude that up to 30 percent of the respondents may have experienced involuntary separations.

The response of older workers to involuntary job loss increasingly differs from that of the general population as their employment horizon shortens in anticipation of retirement. Approximately a quarter of the HRS displaced respondents never get reemployed, and those who do take 1.8 times longer than non-displaced older workers to find a new job. To illustrate the relationship between job loss and the labor market outcomes of older displaced workers, I follow the literature on job displacement (Davis and von Wachter 2011; Jacobson, et al. 1993; Jarosch 2015) and estimate a set of reduced form statistical models that quantify the impact of involuntary job loss on post-displacement earnings, employment and wages. The main findings from these regressions are graphically summarized in Figure 1. Details of the methodology and complete estimation results are provided in Appendix A.

\section{[FIGURE 1]}

The left panel of Figure 1 plots the estimated post-displacement employment rate relative to the employment rate of counterfactual non-displaced workers over ten years after job loss. In the year of involuntary separation, the employment rate falls by 57 percent. Two thirds of the initial losses are recovered within two years, but then the recovery slows down. An employment gap of 13 percent persists after eight years. It finally closes ten years after displacement, in part as both displaced and non-displaced workers keep on retiring from the labor force. The right panel of Figure 1 plots analogous results for earnings which also fall sharply immediately after displacement and show little improvement beyond the first two years of recovery. Unlike employment, earnings do not recover fully and remain almost 20 percent lower than the counterfactual even ten years after displacement. The wage loss remains stable over ten year period and on average 
constitutes 9 percent of the counterfactual.

These estimates imply that over the remaining lifetime displaced workers on average spend thirteen months less in employment. Assuming a discount rate of 4 percent, earnings losses of displaced workers over a ten year period amount to 28 percent of the present discounted value of their earnings, which is equivalent to 1.09 of their annual pre-displacement earnings. The model developed in this paper quantitatively matches these reduced form relationships and demonstrates how the estimates of the fixed effects displacement regressions are affected by selection bias. It also takes the analysis further by answering a range of questions that cannot be addressed within a regression setting.

The gap between the estimated earnings and wage losses suggests that both the wage drop and job market frictions contribute to the total cost of job loss. In addition, these two channels interact with the process of asset accumulation and individual responses to the wealth shocks and interest rates changes. Since the job search process, observed post-displacement wages, labor supply and saving are jointly endogenous, we cannot quantify the relative importance of these forces within a reduced-form regression framework. These dynamic decisions reflect individual expectations, which are best understood in the context of a structural model. Consequently, in the rest of the paper I develop and estimate a dynamic model of retirement with endogenous job search, labor supply and asset accumulation. I then use the model to quantify the contribution of the labor market conditions to the cost of job loss, and to disentangle the impact of the labor market and asset shocks on the retirement decisions.

\section{Model of labor supply, search and retirement}

I now develop a dynamic life cycle model of labor supply and retirement with search frictions and stochastic returns on assets. The model describes the decision problem of an older worker who faces uncertainty about available employment opportunities, wages, asset returns, health, medial expenses, and survival. In each period of life, individuals 
make decisions on their labor supply, consumption and savings, job search, and the take up of Social Security. The model incorporates essential Social Security rules, taxes, unemployment insurance, government transfers, Medicare and intentional bequests. It accounts for individual heterogeneity in terms of the lifetime earnings, year of birth, the risk of layoff, and access to health insurance. The model provides a salient framework to analyze the impact of job loss and volatility of asset returns on the labor market behavior of older workers. I proceed with discussion of the key elements of the model.

\subsection{Preferences}

The time period in the model equals to one month. Each month, an individual aged $t=t_{0}, t_{1} \ldots, t_{T}$ derives utility from consumption $C_{t}$ and leisure $L_{t}$. Individuals belong to different types $\tau^{i}$ determined by the year of birth, lifetime earnings, the risk of being laid off, and access to employer provided health insurance. The within-period utility function is nonseparable in consumption and leisure as in French and Jones (2011),

$$
U\left(C_{t}, L_{t}\right)=\frac{1}{1-\theta_{2}} \cdot\left(C_{t}^{\theta_{1}} L_{t}^{1-\theta_{1}}\right)^{1-\theta_{2}}
$$

Parameter $\theta_{1} \in[0,1]$ is the weight placed on consumption, and $\theta_{2} \geq 0$ determines the degree of risk aversion.

Individuals face exogenous mortality risk. An agent at age $t$ survives to age $t+1$ with probability $\pi_{t}\left(H_{t}, \tau^{i}\right)$ that depends on age, health $H_{t}$ and individual type $\tau^{i}$. Everyone dies with probability one upon reaching the terminal age $t_{T}$. Individuals who die leave all remaining assets as bequest to their heirs. The value of bequest in the amount $A_{t}$ is determined by a bequest function

$$
b\left(A_{t}\right)=\frac{b_{1}}{1-\theta_{2}} \cdot\left(b_{2}+A_{t}\right)^{\theta_{1}\left(1-\theta_{2}\right)} .
$$

This formulation has been derived as a reduced form of an altruistic bequest motive in 
the overlapping generations model by Abel and Warshawsky (1988), and later used to study saving decisions of the elderly (e.g. De Nardi 2004; De Nardi, et al. 2010). The coefficient $b_{1} \geq 0$ captures the strength of the bequest motive, while $b_{2} \geq 0$ characterizes the curvature of the bequest function and determines the extent to which bequests are a luxury good.

\subsection{Time constraints}

The quantity of consumed leisure depends on the amount of labor hours $N_{t}$ supplied out of a fixed endowment $L>0$, the fixed cost of work, health, and the cost of job search:

$$
L_{t}=L-N_{t}-\left(\phi_{0}+t \cdot\left(\phi_{1}+\psi \cdot \mathbb{1}\left\{H_{t}=0\right\}\right)\right) \cdot \mathbb{1}\left\{N_{t}>0\right\}-\varrho \cdot s_{t} .
$$

The two indicator functions denote respectively bad health status $\left(H_{t}=0\right)$ and labor force participation $\left(N_{t}>0\right)$. The job search decision, $s_{t}=\{0,1\}$, assigns the value one to actively searching individuals and zero to everyone else. The time constraints (3) say that the maximum amount of leisure equals to the entire time endowment which is further reduced depending on labor supply, search and health status.

First, the leisure of employed individuals is decreased by the number of hours worked and the fixed cost of work. The fixed cost of work is a linear function of age, $\phi(t)=$ $\phi_{0}+\phi_{1} t$, with non-negative intercept and slope, $\phi_{0}, \phi_{1} \geq 0$. Next, work requires more effort of individuals with serious health problems, and hence those who stay employed in spite of illness lose additional $t \psi$ hours of leisure a month. Finally, unemployed individuals looking for work $\left(s_{t}=1\right)$ have to sacrifice $\varrho$ hours a month to search related activities. These are their search costs. 


\subsection{Budget constraints}

Individuals collect taxable income $Y_{t}$ from wage earnings, Social Security and unemployment benefits:

$$
Y_{t}=N_{t} \cdot W_{t} \cdot\left(1-d_{1} \cdot \ell_{t}\right) \cdot\left(1-d_{2} \cdot \mathbb{1}\left\{N_{t}<120\right\}\right)+S S B_{t}\left(T_{t}^{a}, \tau^{i}, \tau^{s s}\right)+B_{t} .
$$

Wage earnings are determined by the wage rate $W_{t}$ and the hours of labor supply $N_{t}$. The binary indicator of layoff status $\ell_{t}=\{0,1\}$ takes a value of one if a worker has ever been laid off from a job and zero otherwise. The wages of displaced workers are permanently reduced by a factor $d_{1} \in[0,1]$. This reduction is interpreted as a loss of human capital or obsoleteness of skills that caused a layoff. If a worker chooses part-time employment, his hourly wage rate is decreased by a factor $d_{2} \in[0,1]$. This parameter accounts for an empirical pattern of part-time workers earning substantially less than comparable full-time workers after adjusting for the number of hours worked.

The size of the Social Security benefits, $S S B_{t}(\cdot)$, is calculated based on the age at the time of take up $T_{t}^{a}$, individual type $\tau^{i}$ and parameters of the Social Security system $\tau^{S S}$. Individuals who have applied draw a constant stream of benefits until death. Unemployment benefits $B_{t}$ are limited to the actively searching unemployed. In the model, unemployment benefits are assigned conditional on search with probability $\lambda_{B} \in[0,1]$ to avoid keeping track of the unemployment durations that would be computationally infeasible.

The assets $A_{t}$ of an individual belonging to type $\tau^{i}$ are invested at the rate of return $r_{t, \tau^{i}}$ that varies over time. The rate of return depends on the type of worker and accounts for the structure of portfolios held by investors in different income brackets. No borrowing is allowed, $A_{t} \geq 0$. The budget constraint is

$$
A_{t+1}=A_{t}+y\left(Y_{t}+r_{t, \tau^{i}} \cdot A_{t}, \tau\right)+G_{t}-M_{t}\left(H_{t}, I_{t}, \tau^{i}\right)-C_{t},
$$


where function $y(\cdot, \tau)$ gives after tax income for a tax code $\tau$ and $G_{t} \geq 0$ is government transfers. $M_{t}(\cdot)$ is out-of-pocket medical expenses that depend on health, access to health insurance $I_{t}$, and individual type. The budget constraints (5) state that the value of assets in the period $t+1$ is determined from the previously accumulated assets $A_{t}$ augmented by the total value of the current period's after-tax and non-taxable income net of expenditures on consumption and healthcare.

In the data, assets are measured with an error $\varepsilon_{t}^{a}$ that reconciles the model output with observed individual decisions:

$$
\begin{aligned}
\widehat{A}_{t} & =A_{t} \cdot \exp \left(\varepsilon_{t}^{a}\right) \\
\varepsilon_{t}^{a} & \sim N\left(0, \sigma_{\varepsilon^{a}}^{2}\right) .
\end{aligned}
$$

The government provides a minimum consumption level $\underline{C}>0$ through transfers $G_{t}$ according to the rule

$$
G_{t}=\max \left\{0, \underline{C}-\left[A_{t}+y\left(Y_{t}+r_{t, \tau^{i}} \cdot A_{t}, \tau\right)-M_{t}\left(H_{t}, I_{t}, \tau^{i}\right)\right]\right\},
$$

as in Hubbard, et al. (1995). For those receiving government transfers, after tax income in this formulation reduces the amount of government transfers dollar for dollar. Individuals must totally deplete personal assets before gaining access to the consumption floor provided by the government, and the entire amount of received transfers must be consumed in the current period. Government transfers in the model serve as an aggregate approximation for all public transfer programs other than unemployment insurance and Medicare.

\subsection{Retirement channels}

Empirically, most cases of retirement from the labor force take the form of discontinuous transitions from full-time employment to non-work. A standard life cycle model with 
continuous hours of labor supply cannot capture these transitions because workers smooth their consumption and leisure over time and retire by gradually reducing the hours of work. In this paper, several mechanisms jointly generate sharp retirement from the labor force that is consistent with the data.

The first mechanism is represented by the fixed cost of work and the cost of ill health that operate through the time constraints. As workers grow older and their health deteriorates, they have to give up increasing amounts of their leisure endowment in order to stay employed, which results in sharp transitions from work to retirement. Second, retirement is generated by non-linearities in the budget constraints created by the Social Security and Medicare policies. Wages, which decrease with age to reflect declining productivity, also contribute to retirement through the budget constraints. Finally, sharp retirement is generated by the labor market frictions. This last channel first proposed here distinguishes the paper from the rest of the literature.

\subsection{Recursive formulation}

The vector of state variables $S_{t}$ for an individual of type $\tau^{i}$ alive at age $t$ includes the wage rate, medical expenses, health status, and assets. The state is also described by the employment and search decisions made in the previous period, the age of Social Security take up, job offer indicator $\omega_{t}=\{0,1\}$, layoff experience, the draw of unemployment benefits and the history of shocks to the labor markets and asset returns:

$$
S_{t}\left(\tau^{i}\right)=\left(W_{t}, M_{t}, H_{t}, A_{t}, N_{t-1}, s_{t-1}, T_{t-1}^{a}, \omega_{t}, \ell_{t}, B_{t},\left\{\lambda_{k, \tau^{i}}, \delta_{k, \tau^{i}}, r_{k, \tau^{i}}\right\}_{k=t_{0} \ldots t}\right) .
$$

Given the current labor force status, an individual makes decisions $D_{t}$ about the levels of consumption and savings, labor supply, job search and take up of Social Security. The vector of decision variables is $D_{t}\left(S_{t}\right)=\left(C_{t}, N_{t}, s_{t}, T_{t}^{a}\right)$. The number of labor supply hours $N_{t}=0$ for nonworkers, and $N_{t} \cdot s_{t}=0$, which rules out on-the-job search.

Timing in the model is as follows. In the beginning of each period an individual can 
be working, unemployed and looking for work, or out of the labor force. All individuals regardless of their labor force status start the period with receiving two exogenous shocks that determine their health state and medical expenses. Because of the large spread of treatment costs for various conditions with similar overall impact on health, two persons in the same state of health may face very different medical expenses. Even in case of the same diagnosis, the cost of care may be different depending on the provider, for example primary physician compared to an emergency room. Hence the health shock determines the mean of medical expenses through the state of health, while a separate medical expenses shock generates variance that is high enough to match the data.

Employed individuals receive another type-specific shock that destroys their jobs with probability $\delta_{t, \tau^{i}} \in(0,1)$. Workers who did not lose their jobs then obtain updated information on their wages. In the meantime, non-employed individuals get wage offers with probability

$$
\lambda_{t, \tau^{i}}\left(s_{t}\right)= \begin{cases}\lambda_{t, \tau^{i}}^{n} \in(0,1) & \text { if } s_{t}=0 \\ \lambda_{t, \tau^{i}}^{u} \in(0,1) & \text { if } s_{t}=1\end{cases}
$$

where $\lambda_{t, \tau^{i}}^{u}>\lambda_{t, \tau^{i}}^{n}$ are respectively job finding probabilities for unemployed and nonparticipating. While the model in principle allows for getting an offer without search, the chances are much smaller than when an effort is put into searching for employment opportunities. In addition, only the unemployed who have been searching for jobs in the previous period may receive unemployment benefits with probability $\lambda_{B}$. Once the wages are revealed, workers who retained their jobs or received new offers make labor supply decisions.

Workers who just lost their jobs or quit, unemployed who did not receive acceptable offers, and workers who have been out of the labor force decide whether they want to invest time into looking for work. If they decide to search, they start the next period as active unemployed, have a higher chance to receive a job offer and may retain their 
unemployment benefits. Otherwise they enter the next period being out of the labor force.

Next, all individuals make decisions on the Social Security application, on whether to collect income, pay medical expenses and taxes, enjoy leisure, consume and save. Finally, they receive a survival shock and either move to the next period or die and leave bequests.

In each period and state $S_{t}$, an individual chooses a decision rule $D_{t}$ to maximize discounted expected lifetime utility subject to the exogenous processes for mortality, employment, health, medical expenses and wage determination, a set of time and budget constraints (3) and (5), the government transfer rule (7), and policies for taxes, unemployment benefits and Social Security. The discount rate for future payoffs is $\beta$. The values of states with and without a wage offer, $V_{t}^{w}$ and $V_{t}^{n}$, are defined recursively. The value of a state with a wage offer contains four additive terms: the current utility from consumption and leisure and the expected present values of unemployment in case of layoff, employment if not affected by job loss, and utility of bequest if the worker does not survive to the next period:

$$
\begin{aligned}
& V_{t}^{w}\left(S_{t}, D_{t-1}, \theta\right)=\max _{D_{t}}\left\{U_{t}\left(S_{t}, D_{t}, \theta\right)+\right. \\
& \beta \cdot\left[( 1 - \pi _ { t } ) \cdot \left(\delta_{t, \tau^{i}} \int V_{t+1}^{n}\left(S_{t+1}, D_{t}, \theta\right) \cdot p\left(d S_{t+1} \mid S_{t}, D_{t}, \theta_{p}\right)+\right.\right. \\
& \left.\left.\left.\quad\left(1-\delta_{t, \tau^{i}}\right) \int V_{t+1}^{w}\left(S_{t+1}, D_{t}, \theta\right) \cdot p\left(d S_{t+1} \mid S_{t}, D_{t}, \theta_{p}\right)\right)+\pi_{t} b\left(A_{t+1}\right)\right]\right\},
\end{aligned}
$$

where $\theta=\left\{\theta_{s}, \theta_{p}\right\}$ is a vector of model parameters that includes parameters of the state transition probability function $\theta_{p}$ and structural parameters $\theta_{s}$. Similarly, the value of a state without a wage offer, $V_{t}^{n}$, is

$$
\begin{aligned}
& V_{t}^{n}\left(S_{t}, D_{t-1}, \theta\right)=\max _{D_{t}}\left\{U_{t}\left(S_{t}, D_{t}, \theta\right)+\right. \\
& \beta \cdot\left[( 1 - \pi _ { t } ) \cdot \left(\lambda_{t, \tau^{i}}\left(s_{t}\right) \int V_{t+1}^{w}\left(S_{t+1}, D_{t}, \theta\right) \cdot p\left(d S_{t+1} \mid S_{t}, D_{t}, \theta_{p}\right)+\right.\right. \\
&\left.\left.\left.\left(1-\lambda_{t, \tau^{i}}\left(s_{t}\right)\right) \int V_{t+1}^{n}\left(S_{t+1}, D_{t}, \theta\right) \cdot p\left(d S_{t+1} \mid S_{t}, D_{t}, \theta_{p}\right)\right)+\pi_{t} b\left(A_{t+1}\right)\right]\right\}
\end{aligned}
$$


Because the model does not have a closed form solution, the decision rules it generates must be found numerically. I use backward induction to solve the value functions at monthly time intervals. In estimation, the terminal age is set to 100, the maximum working age to 75 , the starting ages to the age of each type in 2000, and part-time work is under 120 hours per month. ${ }^{4}$ I estimate the structural parameters of the model using the method of simulated moments.

\section{Data}

I estimate the model using the Health and Retirement Study (HRS), HRS RAND dataset (version P), and the restricted HRS data on earnings records from the Social Security Administration (SSA). I extract the variables from twelve waves of the HRS that cover a period from 1992 to 2014 at biennial intervals. In this section I describe the sample and variables and explain how I use the data to draw initial conditions for the structural estimation of the model.

\subsection{Sample construction and variables}

The estimation sample consists of white non-Hispanic males age fifty and older. I further restrict the sample to moderate the diversity of paths that respondents may take within the system of Social Security benefits. First, I drop individuals who started receiving Social Security before turning sixty two as well as the beneficiaries of the Supplemental Security Income and Social Security Disability Insurance (SSI/SSDI). These conditions aim to exclude workers with disabilities who may have quite different health transition processes, access to health insurance and non-labor income. Second, I eliminate anyone with total employment record under ten years or over ten years of work in the government. These respondents would either not qualify for Social Security, which requires ten years

\footnotetext{
${ }^{4}$ Setting the maximum working age reduces the dimensionality of the problem. Only $10 \%$ of the HRS estimation sample is employed after 75 , and less than $3 \%$ holds full-time jobs.
} 
of contributions, or have access to the government pension schemes that are not modeled in the paper. The sample resulting from these restrictions contains information on 9,402 individuals, or 56,848 person-year observations.

To estimate the processes that govern the state transition probabilities, I use information on labor supply, wages and average lifetime earnings, assets, mortality, health, medical expenses, and health insurance. Except for the average lifetime earnings and information on layoffs, all variables are taken from the HRS RAND file. The monetary values are converted into constant 2000 dollars. The SSA data allows me to compute the average lifetime earnings. In addition, I construct a proxy of the SSA's average indexed monthly earnings (AIME) by indexing wages to year 2000 and taking an average of the top 35 values, replaced by zeroes if not enough years were reported. Indexing is done with the national wage index. I impute the missing values of medical expenses, average lifetime earnings and wages using a regression based procedure (David, et al. 1986). ${ }^{5}$

Labor supply is computed as a product of the usual hours of work in a week and the average number of weeks in a month. Search decisions are constructed from information on the current labor force status and questions about job search activities. Layoff incidents and the calendar months in which they happen are extracted from self-reported employment histories and separation reasons, as described in Appendix B.1. Assets are measured as the net value of financial and housing wealth of the household. They account for the value of housing, vehicles, businesses, ownerships in IRA, financial instruments and investment funds, and other savings and debt. Assets do not include the value of pensions. I discuss the implications of this restriction in Appendix B.2.

Health status is a binary variable based on the question that asks respondents to evaluate their own health on a five-point scale as excellent, very good, good, fair, or poor. I define health status as good for the top three categories, and bad otherwise.

\footnotetext{
${ }^{5}$ The fractions of the imputed values of medical expenses and lifetime earnings that are used in the computations is 2.8 percent and 2.5 percent, respectively. Missing earnings data arise because only about three quarters of the respondents granted access to their administrative records.
} 
Medical expenses are individual out-of-pocket payments for health care. These expenses include the cost of stays in the hospitals and nursing homes, visits to doctors and dentists, outpatient surgeries, prescription drugs, home health care, and special facilities paid by the respondent in a two-year reference period. They do not include expenses covered by health insurance, but do include insurance premiums paid by the respondent.

Access to health insurance is described by a categorical variable that takes three values: health insurance provided by the current or previous employer to respondents under 65, respondents older than 65 covered by Medicare, and respondents younger than 65 not insured by employer. The last category involves individuals without any health insurance (61 percent) as well as insured by privately purchased plans (39 percent). Both groups pay higher medical expenses on average, either as insurance premiums or as direct cost of health services. I exclude from the estimation of state transition probabilities for medical expenses individuals whose only insurance comes from their spouse's employer or government plans other than Medicare, such as Medicaid, CHAMPVA and TRICARE. These respondents together account for 3.6 percent of the estimation sample, with the largest share (3 percent) made up by those insured through the employers of the spouses.

\subsection{Individual heterogeneity and the initial distribution of state variables}

To estimate the structural parameters of the model, I only use eight waves of the HRS data covering the period from 2000 to 2014. Earlier waves are excluded because of the changes in the Retirement Earnings Test that took place in 2000 and substantially changed the policy environment for employment decisions of older workers. I draw initial conditions for the joint distribution of state variables from a sample of individuals born between 1938 and 1943. The model starts in 2000 when these respondents were between 57 and 62 years old. After accounting for missing data, these restrictions leave 422 persons with complete information available in 2000 who are eligible for initial state draws. A larger sample of 
1,120 individuals with 5,450 available person-year observations is used to compute the moments matched in the estimation.

The model distinguishes between thirty six individual types. Each type is defined by the year of birth, position in the distribution of earnings, and the risk of being laid off. The six birth year types are essential in establishing the age of laid off workers at different stages of the business cycle. They form the basis of inference on the impact of cyclical fluctuations in the asset values, job loss and job finding probabilities on the labor supply of older workers as they approach retirement. Three earnings types are defined by the AIME tertiles. Two layoff risk types, low and high, are identified based on the HRS question that asks respondents to evaluate the likelihood of losing a job within a year. I predict the likelihood of a layoff from a regression of self-reported probabilities on the individual characteristics. An individual is assigned to a high risk type if predicted probability exceeds 0.5, and to a low risk type otherwise. It has been shown in the literature that job loss expectations have a high predictive power for actual job loss (Stephens 2004). Accordingly, my risk indicator appears to be a valid predictor of the actual layoff experiences. The monthly probability of a layoff in the estimation sample is 0.001 for low and 0.003 for the high risk type, a statistically significant difference. The fractions of workers who have experienced job loss in the two groups are 0.132 and 0.293 , respectively.

The initial joint distribution of ages, assets, wage rates, AIME, health, medical expenses, health insurance, labor supply and layoff risk for 10,000 simulated workers is drawn from the $2000 \mathrm{HRS}$ dataset using individual sampling weights. I assume that the initial state summarizes all relevant information from earlier ages, and that it does not reflect any anticipation of future changes to the policy environment, such as reforms of the Social Security or the tax code. Drawing initial conditions from the data accounts for some important empirical relationships between the variables of the model, as reflected in Table 1. The table summarizes descriptive statistics for the initial distribution. For example, the risk of layoff and the rates of unemployment are highest for the low income 
type, a correlation essential for the conclusions of the paper. Individuals with higher lifetime income understandably hold more assets and earn higher wages. The initial state also reflects a complicated connection between financial wellbeing and health. Workers of the highest income type are healthier and pay higher out-of-pocket medical expenditures while being more likely to hold jobs with employer provided health insurance. Heterogeneity in the layoff exposure accounts for an important fact that low skilled workers are more likely to lose their jobs.

[TABLE 1]

\section{Estimation methods}

I estimate the model parameters in two stages similar to Gourinchas and Parker (2002); De Nardi, et al. (2010); French and Jones (2011). First, I obtain the values of the parameters determining exogenous probabilities of transition between the points of the state space that can be identified without using the entire model, $\theta_{p}$. This estimation stage yields the transition processes for health, survival, medical expenses, wages, job loss and job finding, and asset returns. At this stage, I also set up the policy rules for taxes, Social Security and unemployment insurance.

Second, I use the method of simulated moments (McFadden 1989; Pakes and Pollard 1989; Gouriéroux and Monfort 1996) to estimate the structural parameters of the model, while taking the first stage estimates as given. The vector of $m=14$ parameters obtained at the second stage, $\theta_{s} \in \Theta$, includes the coefficients of the utility and bequest functions, the fixed costs of work, health and search costs, wage losses due to human capital depreciation and part-time employment, government transfers, leisure endowment, the probability of getting unemployment benefits, and the variance of measurement error in assets:

$$
\theta_{s}=\left\{\theta_{1}, \theta_{2}, b_{1}, b_{2}, L, \phi_{0}, \phi_{1}, \psi, \varrho, d_{1}, d_{2}, \underline{C}, \lambda_{B}, \sigma_{\varepsilon^{a}}^{2}\right\}
$$


The parameter space $\Theta \subset \mathbb{R}^{m}$ is restricted to account for the lower and upper feasibility boundaries of the parameter values, as dictated by the model.

I exploit five groups of moments for each age between 60 and 70 . These are the rates of employment conditional on health, the fraction of part time workers among the employed, the means of monthly labor supply, the rates of job search among the non-participating, and the quartiles of the asset distribution. In addition, I match the variance of assets and the mean length of an unemployment spell, in total yielding 90 moment conditions.

Technical details of the estimation procedure are provided in appendices. Appendix C describes the estimation of processes for health and wage transition probabilities. Appendix E provides a more detailed description of the MSM estimation. I limit discussion in the rest of this section to the main aspects of the policy environment and aggregate uncertainty.

\subsection{Job finding and layoff probabilities}

The job finding probabilities rely on the gross flows of workers between labor force states. The gross flows are obtained from the rotating part of the basic CPS on males ages 50 and above. ${ }^{6}$ The probability that a worker unemployed in month $t$ will become employed within one month is used as job finding probability for actively searching individuals. The probability of transition from non-participation to employment is used as job finding probability for those who do not search.

Layoff probabilities are computed from the HRS retrospective job histories. I adjust the monthly layoff probabilities by a factor of 1.3 for workers at high risk of layoff and by a factor of 0.5 for workers at low risk. Adjustments are based on the differences of job loss probabilities by layoff risk types in the data, so that the weighted average for the

${ }^{6}$ I use the CPS for job finding and the HRS for layoff probabilities. The CPS gives more accurate information on monthly labor force status and has a larger sample size. Unfortunately it does not have data on separation reasons for workers who have left the labor force, making it unusable for estimation of involuntary separation rates among older workers who often leave the labor force in response to a layoff. 
two types is consistent with the overall probability of involuntary job loss.

I employ twelve month centered moving averages as job finding and layoff probabilities in the model for the months with available data, 2000-2015. Beyond this period, I converge the values to their sample averages over a period of three years. The mean values of the estimated series are $\lambda=0.23$ and $\delta=0.004$. Both probabilities for older workers are lower than their counterparts for all ages. This is consistent with claims in other studies documenting that mobility between labor force states declines with age (e.g. Menzio, et al. 2015).

\subsection{Asset returns and discounting}

The annual discount rate for future payoffs $\beta$ is set equal to 0.96 . Workers invest their wealth in housing, stock and an additional composite asset. The share of wealth invested in each asset depends on worker's income type. Workers of higher income type tend to hold more wealth in stock, while housing is the main asset for those with low lifetime income. Because of such variations in the portfolio structure, any shocks to the housing or stock markets would impact individuals with various levels of wealth differently. I obtain the net values of housing, direct stock holdings and IRA from the HRS RAND data on the composition of assets. Stock holdings reflect both direct stock ownership and the share of IRA invested in stocks, and I take the share of stocks in the IRA from Gustman, et al. (2010). Using these data, I compute the share of each asset in a typical portfolio held by workers of different income types.

The return on portfolio is the weighted average of returns on individual assets. The rate of return on stocks is approximated by returns on large company stock from Ibbotson, et al. (2017). Housing appreciation is based on the FHFA all-transactions index. All returns are twelve-month moving averages of the original series adjusted for inflation. Annualized rate of return on other assets is 4 percent, and the portfolio returns converge to the 4 percent rate over three years after the end of the observed series.

Asset returns, the probability of job finding and the probability of layoff are the three 
sources of aggregate uncertainty in the model. Workers are fully rational and form their expectations of the labor and financial markets based on the least squares forecasts from a linear vector autoregression model of order three as supported by the data.

\subsection{Government}

\section{Social Security}

The model incorporates three major features of the Social Security policy. First, awarded benefits are determined from the primary insurance amount (PIA), a transformation of the AIME over two bend points defined by the SSA. Second, the benefits are subject to the lower and upper limit. Finally, there is a penalty for Social Security take up before the normal retirement age. The earliest Social Security eligibility age is sixty two, and the normal retirement age of the simulated cohorts varies between sixty five and sixty six. Since the model does not offer incentives for delayed retirement, I assume that everybody applies for Social Security upon reaching the normal retirement age. I incorporate these rules into the model with parameter values varying by year of birth. The exact policy rules, institutional details and the values of the parameters used in the simulations are described in Appendix D.

\section{Taxes}

Individuals pay federal, state and payroll taxes. I take the federal tax rates from the annual tax rate schedules, head of household tables. ${ }^{7}$ The state tax rates are taken from 2001 Rhode Island tax rates schedule. ${ }^{8}$ Earnings are subject to Social Security and Medi-

${ }^{7}$ Source: http://www.irs.gov/pub/irs-prior/i1040-2005.pdf

${ }^{8}$ Ideally, I would like to use state tax rates for the respondent's state of residence. Unfortunately, I do not have access to the HRS state identifiers, so I have to impose a uniform state tax. I chose Rhode Island because it was one of the last states to abandon piggyback taxes in 2001. It gives me a straightforward way to estimate tax liability based on federal taxes. French and Jones (2011) claim it to 
care payroll tax at rate of 7.65 percent up to a year specific maximum. Earnings above this maximum are taxed at rate 1.45 percent that only cover Medicare's Hospital Insurance. ${ }^{9}$. The Social Security benefits of early retirees may be taxed in accordance with the Social Security Earnings Test (SSET) as described in Appendix D.

\section{Unemployment insurance}

The amount of unemployment benefits is set to replace 50 percent of pre-displacement earnings, with a maximum of 1,300 dollars per month. The maximum value roughly corresponds to the state average published by the U.S. Department of Labor in 2001 "Comparison of State Unemployment Laws". According to the same source, between January 2000 and December 2014 the average duration of unemployment benefits was 3.8 months. The estimated probability of unemployment benefits reward targets this average.

\section{Baseline estimates of the structural parameters}

In this section, I discuss the estimates and explain how each structural parameter is identified from the data. Furthermore, I show how the model fits the data and highlight the role of search frictions, a new modeling component that is central to the main contribution of the paper.

\subsection{Estimates and identification}

Table 2 contains the MSM estimates of the model parameters and the standard errors. I discuss below each estimate relative to the benchmarks available in the literature, and explain the identification strategy.

be a fairly representative state in terms of income tax rates.

${ }^{9}$ Source: http://www.ssa.gov/oact/progdata/taxRates.html 
Individual preferences are characterized by the parameters of the CRRA utility and bequest functions. The consumption weight, $\hat{\theta}_{1}=0.54$, reflects the relative tastes for leisure and consumption, with higher values implying stronger preference for work. It is identified primarily from the hours of labor supply. The estimate is within the interval obtained by French and Jones (2011) for different values of willingness to work index, $\theta_{1} \in[0.412,0.967]$. The coefficient of relative risk aversion for a consumption-leisure bundle, $\hat{\theta}_{2}=4.9$, and is consistent with the life-cycle retirement literature, e.g. French and Jones (2011) and French (2005). Under the assumption of fixed labor supply, this estimate translates into the coefficient of relative risk aversion for consumption $R(C)=$ $1-\hat{\theta}_{1}\left(1-\hat{\theta}_{2}\right)=3.1$, a conventional measure that is easy to compare to the broad labor supply literature. The coefficient of relative risk aversion is identified by the asset quartiles that reflect the extent of precautionary savings accumulated to insure against adverse income and health shocks.

\section{[TABLE 2]}

The parameters of the bequest function are identified from the upper quartiles of the asset distribution. In the data wealthier individuals keep on saving instead of divesting even after they have accumulated sufficient assets to insure against the risks incorporated into the model environment. The presence of an altruistic bequest motive generates this behavior in the model. In the terminal period $t=t_{T}$ the bequest motive becomes operational once the level of assets reaches the threshold

$$
A_{b}=\hat{b}_{2}\left(\frac{\hat{b}_{1}}{\hat{L}^{\left(1-\hat{\theta}_{1}\right)\left(1-\hat{\theta}_{2}\right)}}\right)^{\frac{1}{\hat{\theta}_{1}\left(1-\hat{\theta}_{2}\right)-1}}
$$

which after adjusting for the scaling of the coefficients gives a value of twenty three thousand dollars. This is the minimum amount of saving an agent needs in order to leave non-zero bequest to an heir instead of consuming the entire amount himself. This amount is low enough to suggest that at the terminal age the bequest motive is operational for the majority of workers. The marginal propensity to consume out of the final period wealth 
is one for individuals whose assets are below this threshold, and $M P C=d C / d A=0.02$ for those who hold more. Analogous relationships can be derived for other ages, hence the maintained level of saving in the top of the wealth distribution and the rate of saving among those whose assets are above the operational bequest threshold jointly identify the intensity of the bequest motive $\hat{b}_{1}=1.008$ and the bequest shifter $\hat{b}_{2}=1.081$.

The monthly time endowment, $L$, is 364 hours, identified jointly by the employment and labor supply moments. The fixed cost of work for a sixty-year-old worker is 60 hours per month. The estimated slope of the linear fixed cost function suggests that over a year the monthly fixed cost of work increases by approximately one hour. Notice that while my model yields approximately the same monthly fixed cost as French and Jones (2011) for a sixty-year-old worker, the age trend is substantially smaller. ${ }^{10}$ The explanation comes from the introduction of labor market frictions in my model, and I discuss it further in Section 6.3. The fixed cost parameters are identified by declining trends in the participation rates and labor supply. The additional cost of work caused by ill health is 0.2 hours per month. This parameter is identified by the rates of labor force participation conditional on health status. The estimated cost of search parameter is 108 hours per month, implying that looking for work takes about the same time as half-time employment. Identification of the cost of search is based on the search intensity moments.

Together these estimated parameters of the utility function and the time constraint capture the way in which workers intertemporally substitute their labor supply. For example, Frisch intertemporal elasticity of substitution for a healthy sixty year old worker employed $N_{60}=160$ hours a month would be approximated by

$$
\eta=\frac{\hat{L}-N_{60}-\hat{\phi}(60)-\hat{\psi}}{N_{60}} \cdot \frac{1-\hat{\theta}_{1}\left(1-\hat{\theta}_{2}\right)}{\hat{\theta}_{2}}=0.567
$$

\footnotetext{
${ }^{10}$ The annual fixed cost of work at age sixty in French and Jones (2011) is $\phi_{P 0}=826$, and the age trend is $\phi_{P 1}=54.7$ hours.
} 
assuming that the borrowing constraint is not binding. This value falls just above the middle of the interval between 0.37 and 0.70 which according to Chetty, et al. (2011) defines the range of the micro estimates for Frisch intensive margin elasticity.

Turning to the parameters of the budget constraint, the most important is the wage loss associated with displacement. It is estimated as 15 percent of the wage received by otherwise similar non-displaced worker. The cost of search and wage loss are identified by the share of non-working individuals who look for work at each age, and by the variation of job finding probabilities across time. The estimate is close to several reference points available in the displacement literature. For example, Couch and Placzek (2010) estimate the mid-term wage losses of displaced workers six years after separation in the range from 13 to 15 percent. Similarly, Davis and von Wachter (2011) find that displaced workers in the U.S. lose 10 to 20 percent of their earnings in the long term depending on whether separation occurred during an expansion or a contraction.

If displaced workers who obtain good wage draws are more likely to stay in the labor market after job loss, wages observed in the data will be biased upwards. The model predicts that one year after job loss wages of reemployed workers will be 14 percent lower than their counterfactual wages if job loss did not occur. However, the wage loss estimated from the simulated data by the fixed effects displacement regression in Section 2 is only 9 percent. This implies that the standard displacement regressions prevalent in the existing literature may underestimate wage losses of reemployed workers by as much as one third, and even more when we consider all workers affected by displacement.

The premium for full time employment, $d_{2}$, is 29 percent of the wage rate. This parameter is identified by the rate of part time employment, and the value is consistent with 25 percent part time employment penalty found by Aaronson and French (2004). The monthly government transfer $\underline{C}=\$ 345$ is identified by lower asset quantiles because guaranteed consumption minimum discourages saving among the poor. In annual equivalent, it is on the same scale as the consumption floor in Hubbard, et al. (1995). 


\subsection{Model fit}

Figure 2 shows the model fit for matched moments. I further provide some results to check whether the model captures some of the data facts that were not directly used in the estimation. The model predicts well the number of workers affected by layoffs over the lifetime and the difference in the timing of labor force exit for displaced and non-displaced workers. Conforming with the data, the share of workers who retire after a layoff grows steadily until peaking at age 65 . The model also reproduces the matrix of transitions between labor force states, with an exception of exit rates from unemployment that are somewhat lower than in the data.

[FIGURE 2]

\subsection{The role of search frictions}

The life-cycle models of retirement from the labor force typically ignore search frictions, allowing for no job destruction and costless access to positive draws from the wage distribution. Usually under these assumptions the transition from work to retirement is driven by changes in wage and non-wage income, health, government policies, or fixed cost of work. I show that search frictions represent an additional incentive to exit the labor force, accounting for up to 20 percent of retirements. Hence, the omission of these labor market frictions results in a nontrivial bias. To show how search affects the model predictions and estimates, I revert to a standard life-cycle retirement model by assuming that jobs are always available $\left(\lambda_{t, \tau}=1\right)$, never destroyed $\left(\delta_{t, \tau}=0\right)$, search is free $(\varrho=0)$, and there is no unemployment insurance $\left(\lambda_{B}=0\right)$. I compare the original model and the frictionless one in two experiments.

In the first experiment, I assume that the labor markets are frictionless and use the estimated model parameters to create a simulated dataset. The employment rate of workers who have reached their normal retirement age in this simulation is on average five percentage points higher than in the data. The fraction of workers retired by the 
age seventy is underestimated by eight percentage points, which is 14 percent of the retirement prevalence at this age. These differences are substantial, and indicate that without search a model of retirement would have to overload other channels in order to match the data.

In the second experiment, I estimate a frictionless model and identify the parameters that turn out to be the most sensitive to the omission of search. I find that the main change occurs in the fixed cost function, increasing the fixed cost of work for a sixty five year old worker by 70 percent. This result appeals to earlier discussions of the role of fixed costs. Rogerson and Wallenius (2013) estimate that the time fixed cost required to generate sharp retirement from the labor force for acceptable values of the intertemporal elasticity of substitution of labor supply exceeds the time required to hold a half-time job. This is implausibly high, and my experiment indicates that one of the reasons is that the fixed costs absorb the role of other retirement incentives that were omitted from the model. By introducing labor market frictions, I explain a portion of this excessive fixed cost, which is an important methodological contribution.

\section{Discussion and counterfactuals}

I now use the model to analyze the impact of involuntary job loss on the labor market outcomes of older workers. Taking full advantage of the structural approach, I construct counterfactual life paths of twin workers who are identical in all initial characteristics and received shocks, except that one of the twins is displaced at some point in his life while the other is not. Comparison of the outcomes of these twin workers over the life cycle yields a flexible tool helpful to evaluate a wide range of job loss consequences.

First, I estimate the impact of involuntary job loss on the labor force attachment of older workers and validate the model by comparing its results to the corresponding estimates of displacement regressions. Next, I compute the cost of displacement in terms of a cash transfer required to compensate a displaced worker for the total lifetime utility 
loss caused by a layoff, a broader measure than the earnings cost of job loss that is often used in the displacement literature. I further decompose the total cost of job loss into two components that are associated with the labor market frictions and post-displacement wage penalty.

Because the incidence and the cost of displacement are both related to the probabilities of losing and finding a job, I consider in a separate section how the cost of job loss and post-displacement labor force attachment vary over the business cycle. Finally, I show how the labor market conditions interact with the asset shocks affecting the retirement of displaced workers. To illustrate this point, I estimate the effect of the Great Recession on the retirement decisions of workers who have reached their late fifties by the beginning of the economic downturn.

\subsection{Labor force attachment after involuntary job loss}

To begin with, I show how displacement affects the labor force attachment and the timing of retirement. I take a sample of older workers and simulate their behavior under several different scenarios. In the first, baseline, scenario workers never lose their jobs even though they anticipate such possibility when making their decisions. In each of the other, displacement, scenarios workers are laid off at a specific age that ranges between 58 and 70. Apart from job loss, in all scenarios, workers receive the same shocks. Therefore, their simulated histories completely coincide with the baseline scenario up to the age of layoff, and any differences after that age are solely ascribed to the job loss. The comparison of the levels of labor supply chosen by workers under the baseline and displacement scenarios shows how labor force attachment is affected by job loss.

Involuntary job loss on average decreases the lifetime labor supply of displaced workers by 2,100 hours, an equivalent of one year's full time work. Coming to fourteen months over the lifetime, the reduction of labor supply following displacement is even larger on the extensive margin. This indicates that displaced workers decrease their labor supply on the extensive as well as intensive margins. Indeed, two years after job loss, displaced workers 
are two and a half times more likely to work part time, and 28 percent less likely to hold a job than if they maintained steady employment. These results are consistent with the reduced form estimates discussed in Section 2. The employment loss due to job loss in the displacement regressions is thirteen months, and the reduction of the employment rate two years after displacement is 35 percent. Because the MSM estimator did not target any moments that characterize the labor supply response to job loss, comparability of these results is essential for model validation.

Finding that job loss is associated with early retirement is consistent with earlier studies (e.g., Chan and Stevens, 2001). However, looking beyond the averages reveals the existence of a sizable group of individuals who respond to job loss by working more in the years following displacement. One in six laid off workers would increase their lifetime labor supply by an average of 2,460 hours, or fourteen months in full time equivalent.

The labor supply response to job loss varies because the choice of retirement time may mitigate the displacement cost in two different ways. On the one hand, early retirement eliminates the need of costly job search. A worker whose expected benefits from finding a job are lower than the expected cost of search would benefit from retiring early. On the other hand, delayed retirement can help recover retirement savings used up during an unemployment spell. The cases of delayed retirement are mainly linked to the interaction between retirement assets and expected future earnings. Displaced workers on average reach the age at which they would have otherwise retired with lower assets than if they had not been displaced, as they would have withdrawn some funds to finance consumption while unemployed. Some of the workers with better wage offers at hand will find it optimal to stay employed and replenish savings. In the simulated data, workers who delay their retirement earn substantially higher pre-displacement wages. Layoffs therefore have a differentiated impact: they are more likely to drive low income workers out of the labor market, while making higher wage earners stay longer.

Because responses to layoffs vary, displacement outcomes in the economy depend on the composition of the affected workers. For example, if job loss only affected low wage 
earners in the bottom 10 percent of the wage distribution, then most of the displaced workers would retire at the same time or earlier and only 11.6 percent would delay retirement from the labor force. However, if affected workers were concentrated in the median 20 percent of the wage distribution, the rate of delayed retirement would rise to 14.5 percent. It would further increase to 27.7 percent if the top 20 percent of wage earners lost their jobs. These experiments speak to the compositions of workers affected by layoffs, since it has been changing over time and is likely to change again in the future. For example, the Great Recession has pushed an unprecedented number of white collar workers into unemployment. This analysis is informative of the way in which the impact of job loss on the transitions from work to retirement depends on the composition of the older workforce, and the possible concentration of layoffs in specific industries or occupations.

\subsection{The cost of job loss}

There is ample evidence that displaced workers suffer from a broad range of negative consequences of the job loss, including earnings and employment instability, deteriorating health, increase in mortality, and adverse effects on family, such as higher divorce rates and lower educational achievement of the children (Davis and von Wachter 2011). Here I measure the cost of job loss for older workers as a monetary transfer required to make a displaced worker indifferent between his current state and otherwise equivalent state in which he was not laid off from a job.

Although a large part of the cost of job loss can be traced to forgone earnings, the full cost is substantially more complicated than the change in the lifetime earnings alone. On the one hand, the full cost amplifies earnings losses by adding non-monetary costs of job loss, including time costs incurred while looking for a new job, the increasing difficulty of working late in life due to the age trends in health and fixed costs of work, disruption of health insurance, and costs associated with non-linearity of the preferences. On the other hand, it accounts for the ability of workers to partially offset the cost of job loss by 
adjusting their labor supply, consumption and Social Security take up decisions. Overall, this measure is broader and more comprehensive than the earnings cost of job loss which is conventionally used in the displacement literature.

Panel A of Figure 3 shows the estimated cost of job loss for each age of layoff between fifty eight and seventy when the probabilities of job loss and job finding are fixed at their long-term averages. On average, the lifetime cost of job loss for workers displaced at these ages amounts to twenty nine thousand dollars, which is about one year of earnings for this age group. The cost of job loss declines with the age of displacement, and the Social Security rules appear essential to understanding this dynamics. Workers displaced in their late fifties bear the highest cost, losing around forty thousand dollars over the remaining lifetime - forty percent more than the average. The cost of job loss falls with the approach of early retirement age, so that workers displaced at sixty two lose 17 percent less than if they lost their jobs four years earlier. The cost of job loss does not change much until the full retirement age when it sharply falls by an additional 23 percent relative to the cost of job loss for fifty eight year olds. It remains consistently high, around twenty thousand dollars, even for workers in their late sixties.

\section{[FIGURE 3]}

To understand the link between the cost of job loss and the Social Security retirement age, recall the previously documented spikes in the rates of labor force exit at early and full retirement ages (e.g. Rust and Phelan 1997). At any age, involuntary job loss is not going to affect the lifetime outcomes of a worker who intended to retire exactly at this age in any event. A mass of workers who plan to leave the labor force around early and full retirement ages will therefore lower the average cost of displacement at these ages. The expected remaining working time of those who reached retirement age is shorter, both because these workers are now older and because they have an option to take up Social Security. The shortening of expected employment time prevents the cost of job loss to increase again after passing the peaks of retirement. Of course, lower averages do not mean that specific individuals are better off being displaced around the normal 
retirement age, as in each case the cost of job loss would depend on the anticipated individual retirement date which may be well past the Social Security age.

To see what generates the cost of job loss, note that displaced workers are adversely affected via two channels. First, they suffer a permanent reduction in future wages. Second, they lose earnings and access to health insurance due to search frictions. The two channels represent respectively intensive and extensive margins of the cost associated with job loss and can be explored separately. The intensive margin can be shut down by eliminating displacement wage penalty $\left(d_{1}=0\right)$, while the extensive margin is removed under the assumption of frictionless labor markets $\left(\lambda_{t, \tau}=1\right.$ and $\left.\varrho=0\right)$.

Decomposing the total cost by channel, I find that in stable economic conditions most of the losses are due to the reduction of post-displacement wages (intensive margin), which accounts for 70 percent of the total. The remaining 30 percent is due to the loss of earnings over the periods of unemployment that follow a job loss (extensive margin). The share of the extensive margin depends on the age of displacement, as shown in Figure 3. Search frictions are relatively more important for workers laid off around the normal retirement age due to the increasing number of displaced workers who give up potential earnings by retiring early without attempting to search. The fraction of costs due to search peaks at displacement age sixty four where it accounts for more than a third of the total.

\subsection{Job loss over the business cycle}

The probabilities of job loss and job finding vary over the business cycle, and their dynamics affect both the incidence and the cost of job loss. In this section, I repeat a set of experiments similar to those from sections 7.1. and 7.2. to estimate the impact of job loss in a recession on the labor force attachment and the cost of displacement.

Workers displaced during a recession face lower probability of job finding and higher chances of repeated displacement. I set the recessionary probabilities of job finding and job loss equal to the estimates obtained at the trough of the Great Recession $\left(\lambda_{\text {rec }}=0.14\right.$ 
and $\left.\delta_{r e c}=0.005\right)$. The benchmark probabilities remain fixed at their long-term average levels as in the previous section. A recession lasts for one year, after which job finding and job loss probabilities revert to their long-term averages.

Business cycle fluctuations exacerbate the negative impact of displacement on the labor force attachment. The lifetime labor supply of older workers displaced in a recession decreases by additional 450 hours, or two and a half months of full time work. Accounting for the extended duration of search, their total time in the labor force is three months lower than that of the identical workers displaced in more favorable economic conditions. Recessions further polarize the response by workers who adjust their hours of work in the opposite directions. Those who work less over the lifetime now supply 14 percent hours less, and those who work more increase the number of hours by additional 12 percent. In monetary terms, these changes in the labor force attachment translate into an additional loss of five thousand dollars over the lifetime, generated almost exclusively by search frictions which in a recession account for 45 percent of the total loss (panel B of Figure $3)$.

Not only do displaced workers lose more if laid off during a recession, there are more displacements that occur in a weak economy. What is the overall impact of an economic downturn, like the Great Recession of 2007-2009, on the labor force attachment of workers who would have planned to retire around this time? To answer this question, I consider an artificial cohort of workers whose age is between 57 and 62 at the end of 2004, just over three years past the trough of the previous recession in November 2001. When the new recession ensues three years later in December 2007, these workers (aged 60-65 by that time) will be hit directly in the process of transition to retirement.

To estimate the impact of the recession on the retirement behavior of this cohort, I simulate two datasets. In the first simulation, the probabilities of layoff and job finding are fixed at their long term averages. The second simulation uses the actual job finding and layoff probabilities registered between the beginning of the simulation period in December 2004 and December 2010, a year and a half past the trough of the Great Recession. This 
experiment introduces labor market cyclicality into the environment of older workers as they transition to retirement. Comparing labor force transitions in the two datasets, I can now discern how the rates of exit from the labor force vary at different stages of the business cycle.

The solid line in Figure 4 represents the percentage difference in the monthly new retirements observed in the simulations with the cyclical probabilities against the benchmark case that uses the long-term averages. The positive and negative values represent respectively higher and lower rates of retirement relative to the stable economy scenario. As the probabilities of job loss and job finding deviate from their average values, the new retirements respond by substantial variation with the range of changes of about 13 percent. The number of new retirements steadily increases throughout the recession, with the peak difference of 7 percent reached in the middle of 2009. With the economy improving, the number of new retirements declines to the low difference point of -6 percent towards the end of 2010. Overall, the entire cohort retires one and a half months earlier in the recession.

[FIGURE 4]

\subsection{Involuntary job loss and the asset shocks}

The results discussed in the previous section show that the cyclical variations in job finding and layoff probabilities are important for retirement behavior, and that more retirements occur when the labor market is weak. Another aspect of the business cycle that is highly relevant for the decision to retire is the performance of financial markets. The retirement wealth of the simulated cohort was depleted as the stock markets shrank by more than 50 percent over a year and a half of the Great Recession, accompanied by a comparable decline in the value of the housing equity. The stock markets also fell by more than 30 percent during the dot-com bubble of the 2000-2002. The estimates of the recession impact would therefore be incomplete without accounting for another major feature of the Great Recession, the negative shock to the returns on assets. 
It is commonly acknowledged that while layoffs accelerate, asset losses postpone retirement. For example, Coile and Levine (2010) document how the media view of the impact that the Great Recession had on retirement evolved over time. Initially envisioning delayed retirement due to the crash of financial markets, it later increasingly turned to the predictions of early retirement caused by unfavorable labor market conditions. As in both recent recessions asset shocks that have affected retirement wealth coincided with the cyclical variations of job finding and layoff probabilities, the total effect of recessions on the retirement behavior of older workers is ambiguous. Using the model, I can isolate the impact of shocks that have affected asset and labor markets on retirement and the cost of job loss.

To model the financial impact of the recession on retirement, I introduce a solitary unanticipated negative shock to the value of assets and compute the resulting change in the timing of retirement. I find that decline in asset returns that takes place while the probabilities of job loss and job finding remain fixed at their long-term average values indeed forces workers to stay in the labor force longer. A 20 percent shock to asset values on average delays retirement by 4 months, while a 50 percent shock produces a delay of almost one year.

Adding the asset shocks to the recession counterfactuals from section 7.3, I can simulate the joint impact of layoffs and asset returns during the Great Recession. The dotted line in Figure 4 shows percentage change in new retirements during the recession once the variation in asset returns has been taken into account. The early retirement peak shifts to the left, so that workers who were not yet fully affected by the negative asset shocks self-select to retire at the very beginning of the recession. Later on however more workers delay retirement from the labor force in an attempt to make up for wealth losses. With both asset and labor market dynamics taken into consideration, I find that workers retiring during the Great Recession would on average postpone retirement by approximately five months. Intuitively, asset losses dominate the final outcome for two reasons. First, the two forces do not entirely cancel each other out as job loss itself leads to delayed 
retirement for some of the displaced workers. Second, fewer people are affected by layoffs than by changes in asset returns, even when the impact of a layoff is bigger in magnitude.

\section{Conclusion}

At least one in five older workers in the United States is affected by involuntary job loss shortly before retirement from the labor force. As the probabilities of job finding decrease with age, displaced older workers experience longer unemployment spells and substantial reduction in earnings over the remaining lifetime. Faced with the difficulty of reemployment, many stop searching and permanently exit the labor force. Involuntary job loss and labor market frictions therefore potentially represent an important retirement incentive. To estimate the cost of job loss for older workers and understand its effect on the transition from work to retirement, I construct a dynamic programming model of retirement with search frictions.

I estimate the structural parameters of the model using the method of simulated moments and the data from the Health and Retirement Study. The model confirms that search frictions and involuntary job loss are essential to understanding of retirement, as they account for 10 percent of the retirement trend. In a frictionless environment, the model predicts that the fraction of retirements otherwise explained by search is predominantly absorbed by the fixed cost of work. This result explains why the fixed costs of work are excessively high in the standard lifecycle models of labor supply and retirement.

The average cost of involuntary job loss measured by a compensation required to keep a worker indifferent between the states of employment and unemployment due to displacement is equivalent to one year of full-time earnings. Seventy percent of this cost is attributed to the post-displacement wage reduction, the rest is due to search frictions. The cost of losing a job in a contraction with job loss and job finding probabilities equal to those observed at the trough of the Great Recession is approximately 15 percent higher. This difference is mainly generated by search frictions that account for a substantially 
larger portion of the total cost during economic downturns.

Displaced workers on average retire about one year earlier than they would have done without a job loss, however 18 percent of the simulated workers postpone their retirement in response to a layoff. The fraction of displaced workers who retire early increases during recessions when the labor market is weak. Yet, in the two most recent recessions, the negative impact of job loss on the lifetime labor supply was partially offset by retirement delay caused by decline in savings as they were hit by the plunge of the stock markets and the housing bubble. I estimate that the simultaneous shocks to the values of assets, layoff and job finding probabilities would lead the cohort of workers who approached retirement age at the onset of the recession to postpone retirement by approximately five months. 
Table 1: Descriptive statistics for the initial state distribution

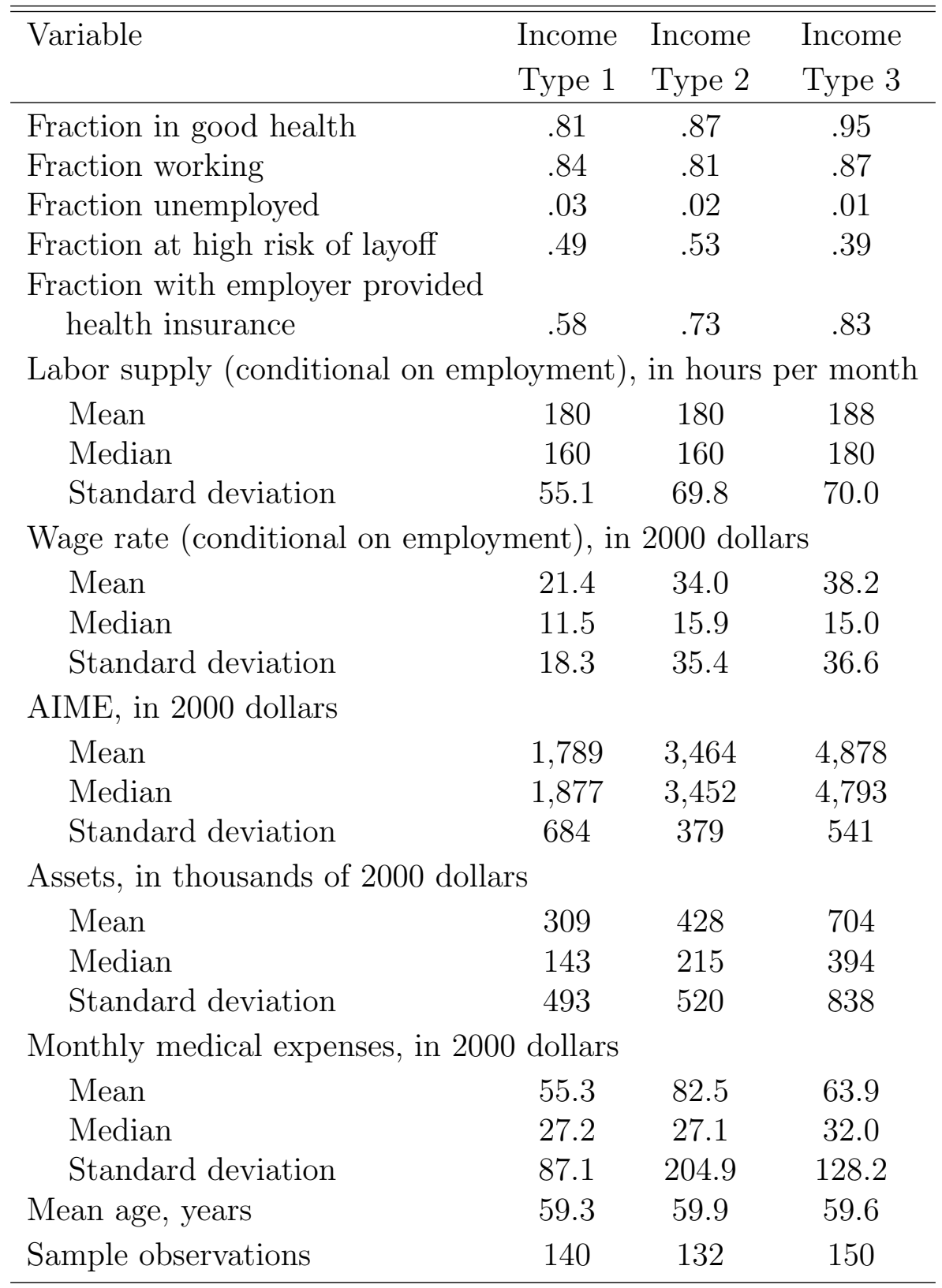

Notes: HRS white non-Hispanic male workers born in 1938-1943 with at least ten years of non-government employment. Excludes early recipients of Social Security (before 62) and recipients of SSI/SSDI. Income types 1-3 correspond to the tertiles of the AIME distribution. 
Table 2: Estimates of structural parameters

\begin{tabular}{lrr}
\hline \hline Parameter & Estimate & $\begin{array}{r}\text { Standard } \\
\text { error }\end{array}$ \\
\hline$\theta_{1}:$ Consumption weight & 0.536 & 0.035 \\
$\theta_{2}:$ Coefficient of relative risk aversion & 4.93 & 0.180 \\
$b_{1}:$ Intensity of bequest motive & 1.008 & 0.098 \\
$b_{2}:$ Bequest shifter & 1.084 & 0.204 \\
$L:$ Monthly leisure endowment, hours & 364 & 22.1 \\
$\phi_{0}:$ Fixed cost of work at 60, hours & 59.8 & 2.69 \\
$\phi_{1}:$ Fixed cost of work, slope & 0.089 & 0.026 \\
$\psi:$ Cost of bad health, hours & 0.186 & 0.027 \\
$\varrho:$ Cost of search, hours & 108 & 25.3 \\
$d_{1}:$ Wage loss due to displacement & 0.150 & 0.013 \\
$d_{2}:$ Wage loss due to part time employment & 0.294 & 0.027 \\
$C:$ Government transfers, USD & 345 & 9.78 \\
$\lambda_{B}:$ Probability of getting unemployment benefits & 0.850 & 0.128 \\
$\sigma_{\varepsilon^{a}}^{2}:$ Variance of the measurement error in assets & 0.205 & 0.010 \\
\hline$\chi^{2}$ statistic $=485$, degrees of freedom $=76$ & & \\
\hline
\end{tabular}

Notes: Method of Simulated Moments estimates of the structural parameters, conditional on exogenous estimates of the state transition probabilities. Initial values of state variables are drawn from the 2000 HRS sample of white non-Hispanic males 50 and older with at least ten years of non-government employment, born in years 1938-1943. Excludes early recipients of Social Security (before 62) and recipients of SSI/SSDI. Estimation uses diagonal weighting matrix. 


\section{References}

Aaronson, D. and E. French, "The Effect of Part-Time Work on Wages: Evidence from the Social Security Rules," Journal of Labor Economics 22 (2004), 329-352.

Abel, A. B. and M. Warshawsky, "Specification of the Joy of Giving: Insights from Altruism," The Review of Economics and Statistics 70(1988), 145-149.

Blau, D. M. and D. B. Gilleskie, "Health Insurance and Retirement of Married Couples," Journal of Applied Econometrics 21(2006), 935-953.

Blau, D. M. and D. B. Gilleskie, "The Role of Retiree Health Insurance in the Employment Behavior of Older Men," International Economic Review 49(2008), 475-514.

Chan, S. and A. H. Stevens, "Job Loss and Employment Patterns of Older Workers," Journal of Labor Economics 19(2001), 484-521.

Chan, S. and A. H. Stevens, "How Does Job Loss Affect the Timing of Retirement?" Contributions in Economic Analysis 85 Policy 3(2004), -.

Chetty, R., A. Guren, D. Manoli, and A. Weber, "Are Micro and Macro Labor Supply Elasticities Consistent? A Review of Evidence on the Intensive and Extensive Margins," The American Economic Review 101(2011), 471-75.

Cogan, J. F., "Fixed Costs and Labor Supply," Econometrica 49(1981), 945-963.

Coile, C. C. and P. B. Levine, "The Market Crash and Mass Layoffs: How the Current Economic Crisis May Affect Retirement," The B.E. Journal of Economic Analysis 
63 Policy 11(2011a), -.

Coile, C. C. and P. B. Levine, "Recessions, Retirement and Social Security," American Economic Review: Papers $\&$ Proceedings 101(2011b), 23-28.

Couch, K. A. and D. W. Placzek, Earnings Losses of Displaced Workers Revisited. The American Economic Review 100(2010), 572-589.

David, M., R. J. A. Little, M. E. Samuhel, and R. K. Triest, "Alternative Methods for CPS Income Imputation," Journal of the American Statistical Association 81(1986), $29-41$.

Davis, S. J. and T. von Wachter, "Recessions and the Costs of Job Loss" Brookings Papers on Economic Activity 2(2011), 1-72.

De Nardi, M., "Wealth Inequality and Intergenerational Links". Review of Economic Studies 71(2004), 743-768.

De Nardi, M., E. French, and J. B. Jones, "Why do the elderly save? The role of medical expenses," Journal of Political Economy 118(2010), 39-75.

Elder, T. E., "Reemployment Patterns of Displaced Older Workers," Manuscript, 2004 .

Farber, H. S., "The Incidence and Costs of Job Loss: 1982-91," Brookings Papers on Economic Activity, 1(1993), 73-119.

French, E. B., "The Effects of Health, Wealth, and Wages on Labour Supply and 
Retirement Behaviour," The Review of Economic Studies 72(2005), 395-427.

French, E. B. and J. B. Jones, "The Effects of Health Insurance and Self-Insurance on Retirement Behavior," Econometrica 79(2011), 693-732.

Goda, G. S., J. B. Shoven, and S. N. Slavov, "What Explains Changes in Retirement Plans During the Great Recession," American Economic Review: Papers $\&$ Proceedings 101(2011), 29-34.

Gouriéroux, C. and A. Monfort, Simulation-Based Econometric Methods (New York: Oxford University Press, 1996).

Gourinchas, P.-O. and J. A. Parker, "Consumption over the Life Cycle," Econometrica 70(2002), 47-89.

Gustman, A. L. and T. L. Steinmeier, "A Structural Retirement Model," Econometrica 54(1986), 555-584.

Gustman, A. L., T. L. Steinmeier, and N. Tabatabai, "What the Stock Market Decline Means for the Financial Security and Retirement Choices of the Near-Retirement Population," Journal of Economic Perspectives 24(2010), 161-182.

Haan, P. and V. Prowse, "A Structural Approach to Estimating the Effect of Taxation on the Labour Market Dynamics of Older Workers," Econometrics Journal 13(2010), S99-S125.

Haan, P. and V. Prowse, "Longevity, Life-Cycle Behavior and Pension Reform," Journal of Econometrics 178(2014), 582-601. 
Hubbard, R. G., J. Skinner, and S. P. Zeldes, "Precautionary Saving and Social Insurance," Journal of Political Economy 103(1995), 360-399.

Ibbotson, R., R. J. Grabowski, J. P. Harrington, and C. Nunes, Stocks, Bonds, Bills, and Inflation Yearbook (Wiley, 2017).

Jacobson, L. S., R. J. LaLonde, and D. G. Sullivan, "Earnings Losses of Displaced Workers," The American Economic Review 83(1993), 685-709.

Jarosch, G., "Searching for job security and the consequences of job loss," Manuscript, 2015.

McFadden, D., "A Method of Simulated Moments for Estimation of Discrete Response Models without Numerical Integration," Econometrica 57(1989), 995-1026.

McFall, B. H., "Crash and Wait? The Impact of the Great Recession on the Retirement Plans of Older Americans," American Economic Review: Papers 85 Proceedings 101(2011), 40-44.

Menzio, G., I. A. Telyukova, and L. Visschers, "Directed Search over the Life Cycle," Review of Economic Dynamics 19(2015), 38-62.

Pakes, A. and D. Pollard, "Simulation and the Asymptotics of Optimization Estimators," Econometrica 57(1989), 1027-1057.

Poterba, J. M. and L. H. Summers, "Response Variation in the CPS: Caveats for the Unemployment Analyst," Monthly Labor Review, 3(1984), 37-43. 
Rogerson, R. and J. Wallenius, "Nonconvexities, Retirement and the Elasticity of Labor Supply," The American Economic Review 103(2013), 1445-62.

Rust, J. and C. Phelan, "How Social Security and Medicare Affect Retirement Behavior in a World of Incomplete Markets," Econometrica 65(1997), 781-831.

Scholz, J. K., A. Seshadri, and S. Khitatrakun, "Are Americans Saving "Optimally" for Retirement?" Journal of Political Economy 114(2006), 607-643.

Stephens, M., "Job Loss Expectations, Realizations, and Household Consumption Behavior," The Review of Economics and Statistics 86(2004), 253-269.

Stevens, A. H., "Persistent Effects of Job Displacement: The Importance of Multiple Job Losses," Journal of Labor Economics 15(1997), 165-188.

van der Klaauw, W. and K. I. Wolpin, "Social Security and the Retirement and Savings Behavior of Low-Income Households," Journal of Econometrics 145(2008), 2142. 